\title{
Coronary CT angiography and stress perfusion scan for evaluation of patients with atypical chest pain
}

\author{
Mehmet Incedayi, ${ }^{1}$ Zafer Isilak, ${ }^{2}$ Ersin Ozturk, ${ }^{1}$ Murat Yalçin ${ }^{2}$
}

${ }^{1}$ Department of Radiology, GATA Haydarpasa Teaching Hospital, Istanbul, Turkey ${ }^{2}$ Department of Cardiology, GATA Haydarpasa Teaching Hospital, Istanbul, Turkey

\section{Correspondence to}

Dr Mehmet Incedayi, m_incedayi@yahoo.com

\section{DESCRIPTION}

A 52-year-old man presented with moderate substernal chest pain lasting for more than $30 \mathrm{~min}$. The pain was independent of exertion and did not respond to nitroglycerine. The patient's medical history includes hypertension, smoking, dyslipidaemia and congenital right hip dysplasia. Physical examination findings were normal. ECG showed normal sinus rhythm. Transthoracic echocardiography revealed a normal ejection fraction of $64 \%$. ECG-gated coronary CT angiography and stress CT perfusion scan was performed. The patient had no contraindication for $\beta$-blockers. CT examination was performed using 320-section scanner (Aquilion-ONE, Toshiba, Japan). A total of $110 \mathrm{ml}$ $(60 \mathrm{ml}$ for coronary CTA and $50 \mathrm{ml}$ for perfusion imaging) iodine contrast agent, iomeprol (Iomeron 400, Bracco, Milano, Italy), followed by $50 \mathrm{ml}$ saline solution, was injected into an antecubital vein through an 18 gauge catheter at a flow rate of $5 \mathrm{ml} / \mathrm{s}$ using an automated power injector (Medrad Envision CT, Pittsburgh, Pennsylvania, USA). After

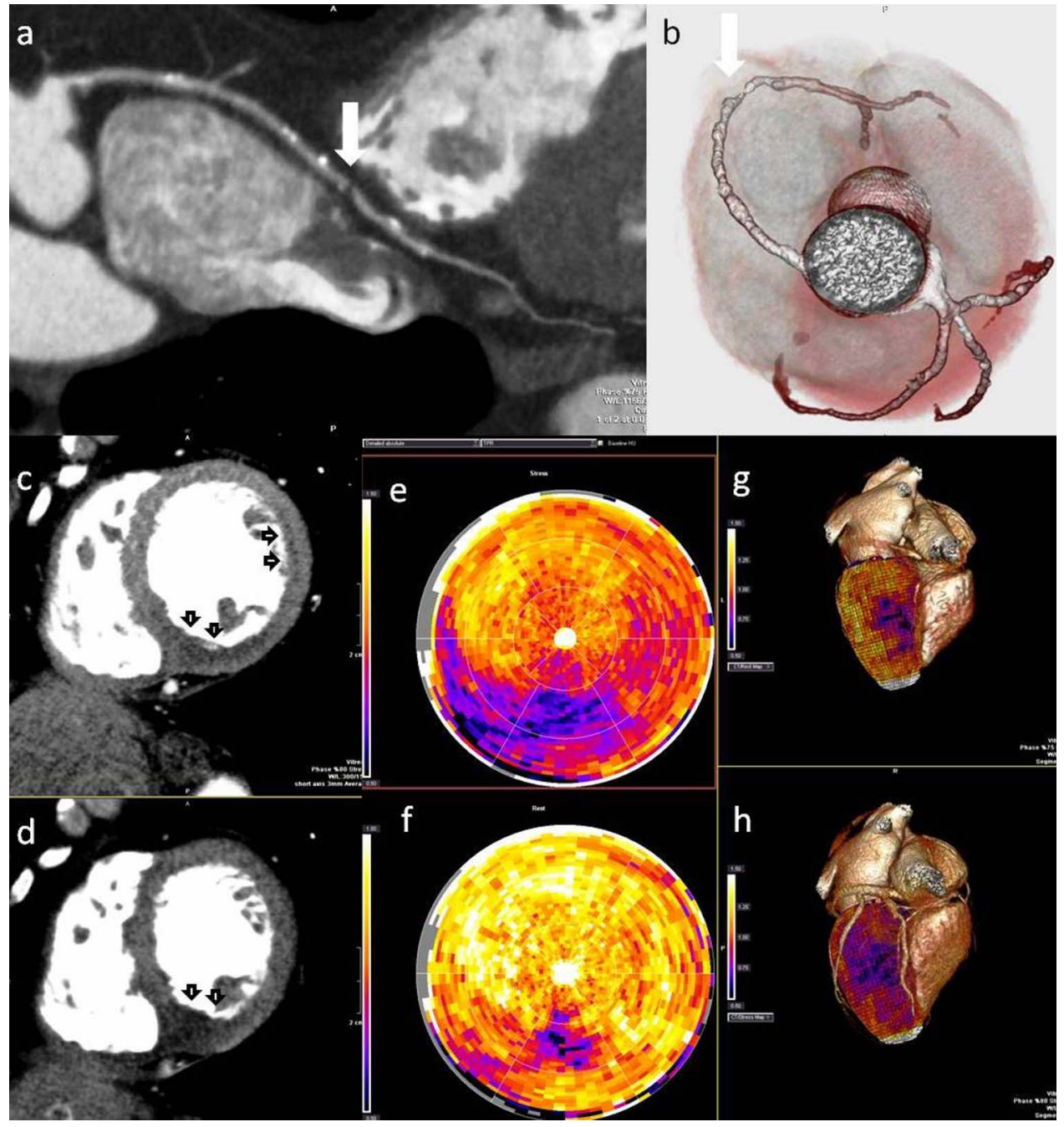

Figure 1 ( $A$ and $B$ ) Coronary $C T$ angiograms demonstrate widespread vascular disease. A soft plaque in the midportion of RCA causes significant stenosis (arrow). (C and D) The rest CTA scan shows hypoperfused region on the inferior wall (corresponds to the vascular territory of RCA). The hypoperfused area on the inferior wall was enlarged and a new hypoperfused area in the subendocardium of the lateral wall of the left ventricle was appeared in the stress CTA scan (arrowheads). ( $E$ and F) The stress transmural perfusion ratio (TPR) map confirms the presence of the inferior wall defect (blue and purple areas). The defect is also seen in the rest of the TPR map but is smaller. That indicates a partially reversible defect. ( $G$ and $H$ ) Fusion of the TPR polar map and the anatomical cardiac three-dimensional image shows relationships between the perfusion defects and coronary vessels. 
a 10 min period (for myocardial contrast wash-out) coronary CT angiography, rest and stress scan for perfusion imaging were performed. Adenosine (pharmacological stress agent) was administered by continuous infusion via a peripheral intravenous line at a rate of $0.14 \mathrm{mg} / \mathrm{kg} / \mathrm{min}$ after $5 \mathrm{~min}$. Blood pressure and heart rate were monitored during infusion. At the end of the study, the images were reconstructed in diastolic phase (figure 1A-H). Later both images were compared and diffuse vascular disease and perfusion defects were detected in the patient. Medical treatment was started and coronary angiography was planned.

\section{Learning points}

- Cardiac multidetector CT has the ability to demonstrate high spatial resolution images and the anatomical structure in a detailed manner, and thus it successfully and rapidly brings the cardiac anatomy, morphology and coronary arteries into light.

- Recently, myocardial perfusion imaging, as a functional imaging modality, is being used with coronary CT angiography. ${ }^{1}$
Competing interests None.

Patient consent Obtained.

Provenance and peer review Not commissioned; externally peer reviewed.

\section{REFERENCE}

1 Wang $Y$, Qin L, Shi $X$, et al. Adenosine-stress dynamic myocardial perfusion imaging with second-generation dual-source CT: comparison with conventional catheter coronary angiography and SPECT nuclear myocardial perfusion imaging. AJR Am J Roentgenol 2012;198:521-9.

Copyright 2013 BMJ Publishing Group. All rights reserved. For permission to reuse any of this content visit http://group.bmj.com/group/rights-licensing/permissions.

BMJ Case Report Fellows may re-use this article for personal use and teaching without any further permission.

Become a Fellow of BMJ Case Reports today and you can:

- Submit as many cases as you like

- Enjoy fast sympathetic peer review and rapid publication of accepted articles

- Access all the published articles

- Re-use any of the published material for personal use and teaching without further permission

For information on Institutional Fellowships contact consortiasales@bmjgroup.com

Visit casereports.bmj.com for more articles like this and to become a Fellow 